\title{
Simultaneous involvement of lungs, larynx and middle ear by tuberculosis -a rare case.
}

\author{
Dr. Iqbal Murshed Kabir', Dr. Ahmed Minhaz Shumon', Dr. Kazi Atikuzzaman ${ }^{3}$, Dr. Yeahyea Zaman ${ }^{4}$, Dr. Atiqur \\ Rahman $^{5}$
}

${ }^{1}$ Associate Professor, Department of Gastroenterology, Dhaka National Medical College, ${ }^{2}$ Associate Professor, ENT Department, Enam Medical College, ${ }^{3}$ Assistant Professor, ENT Department, Enam Medical College, ${ }^{4}$ Junior Consultant, ENT Department, Enam Medical College, ${ }^{5}$ Assistant Professor, Pathology Department, Enam Medical College.

\begin{abstract}
Summary
Simultaneous involvement of lungs, larynx and middle ear by tuberculosis is very rare. We present a rare case of simultaneous involvement of larynx and ear in a patient with pulmonary tuberculosis. A 17 years old male presented with fever and cough for 8 months, bilateral deafness for 5 months and hoarseness of voice for 3 months. The patient gave history of anorexia and progressive weight loss and history of close contact with tuberculosis patient. There were coarse crepitations on auscultation of both lungs. Indirect laryngoscopy revealed diffuse nodular swelling as well as thickening of the vocal cords. Examination of both ears revealed pale-yellow granulation tissue. ESR was $94 \mathrm{~mm}$ in $1^{\text {st }}$ hour and chest radiograph showed diffuse patchy opacities extending over both lung fields. The results of two sputum examinations showed numerous acid-fast bacilli Histopathologic examination of punch biopsy from right and left ear lesions and biopsy tissue from laryngeal lesion taken by endoscopic instrument revealed granulomatous inflammation histologically consistent with tuberculosis. The patient responded well and promptly to the antituberculous therapy. The aim of this article is to create an awareness of Ear Nose Throat tuberculosis and to consider tuberculosis in the differential diagnosis of ear and laryngeal diseases and to emphasize the need for prompt recognition and treatment.
\end{abstract}

Key Words: Tuberculosis, pulmonary, laryngeal, otitis media.

\section{Introduction:}

Although tuberculosis is not common in developed countries, it is common in developing countries like Bangladesh. Among the forms of involvement in extrapulmonary tuberculosis are the otolaryngological manifestations of this disease, mainly represented by cervical lymphadenopathy, laryngeal tuberculosis, tuberculous otitis media (TOM), tuberculous involvement of the nasal and oral cavity and oropharynx(1). Laryngeal TB accounts for less than $1 \%$ of all TB cases(2) and it is estimated that the involvement of the larynx occurs around $1 \%$ of patients with pulmonary tuberculosis (3). Laryngeal TB is highly contagious and misdiagnosis can pose a serious risk to the public health(4).

Tuberculous otitis media is generally considered a disease of children and young adults, as patients $<15$ years of age account for $84 \%$ of all cases.(5) The most common route of tuberculous otitis media (TOM) infection is via the Eustachian tube and hematogenous, being the second most common (6).
Ninety percent of cases of laryngeal tuberculosis are associated with pulmonary TB (2) The prevalence of active or inactive pulmonary TB in patients with TOM ranges from 14 to $93 \%$. However, up to 40 to $50 \%$ of patients with TOM may have no evidence of TB elsewhere (7).

Simultaneous involvement of lungs, larynx and middle ear by tuberculosis is very rare. We present a rare case of simultaneous involvement of larynx and ear in a patient with pulmonary tuberculosis.

\section{CASE REPORT}

A 17 years old male presented with fever and cough for 8 months, bilateral deafness for 5 months and hoarseness of voice for 3 months at outpatient department of Enam Medical College Hospital. The fever was low grade and intermittent in nature with evening rise without chills and rigor. Alongwith the progressive deafness, the patient also had occasional earache and aural discharge. The patient gave history of anorexia and progressive 
J. Dhaka National Med. Coll. Hos. 2011; 17 (01): 53-55. weight loss. There was history of close contact with tuberculosis patient. On examination, the patient looked thin and distressed by persistent cough and hoarseness. There were coarse crepitations on auscultation of both lungs. Indirect laryngoscopy revealed diffuse nodular swelling as well as thickening of the vocal cords. The mobility of the right side of the larynx was limited. Examination of both ears revealed pale-yellow granulation tissue on a thickened and hyperemic tympanic membrane. Laboratory tests showed ESR was $94 \mathrm{~mm}$ in $1^{\text {st }}$ hour, $\mathrm{Hb} 10.3 \mathrm{~g} / \mathrm{dl}$. MT test result was 22 $\mathrm{mm}$ after 72 hours. Chest radiograph showed diffuse patchy opacities extending over both lung fields. The results of two sputum examinations showed numerous acid-fast bacilli. Histopathologic examination of punch biopsy from right and left ear lesions revealed granulomatous inflammation histologically consistent with tuberculosis. Histopathology of biopsy tissue from laryngeal lesion taken by endoscopic instrument showed similar result. The patient then received a conventional antituberculosis regimen consisting of isoniazid, rifampin, pyrazinamide, ethambutol, and streptomycin. The patient responded well and promptly to the antituberculous therapy. At the two-month follow up, his symptoms almost completely subsided and he regained weight. The laryngoscopy revealed almost complete resolution of laryngeal swellings and lesions with only mild hyperemia left in the right ventricular region. $\mathrm{He}$ had dramatic otologic response with resolution of granulation tissue over 2 to 3 weeks. Follow-up chest radiograph showed resolution of the pulmonary shadows.

\section{Discussion}

Tuberculosis is a global problem for the last 20 years and had clinical pattern of involvement different from the current one. This change, as well as increasing number of reported cases may be associated with the onset of AIDS (8).

This disease is an infection with its primary etiologic agent Mycobacterium tuberculosis. This has the sole natural reservoir, the human body (9) and is transmitted via airborne particles, released into the air by talking, coughing or sneezing by a patient with contagious TB. Anybody can be affected by the bacillus and extrapulmonary involvement is usually secondary to pulmonary involvement and may be difficult to diagnose (10).
Due to uncommon clinical presentations and lack of clinical suspicion, laryngeal TB is frequently confused with other laryngeal disease such as chronic laryngitis and laryngeal carcinoma $(11,12)$. The most common site of involvement is the laryngeal vocal fold (50-70\%), followed by ventricular band (40-50\%) and the remaining $10-15 \%$ may involve the epiglottis, aryepiglottic fold, arytenoids, posterior commissure and subglottis(3). The process of destruction and repair often proceeds simultaneously. Hoarseness is the common symptom of laryngeal tuberculosis, present in over $90 \%$ of patients.

The clinical manifestations of tuberculous otitis media vary greatly, but the most common feature is an aural discharge of insidious onset. Most patients also experience an associated acute-onset hearing loss that is disproportionate to the extent of the disease (13). Characteristically, there is little or no otalgia(14).The pathogenesis of tuberculous otitis media involves one of three major mechanisms: (1) aspiration of mucus through the eustachian tube, (2) blood-borne dissemination from other tuberculous foci, or (3) in rare cases, direct implantation through the external auditory canal and a tympanic membrane perforation(13).

In diagnosing tuberculous otitis media, it is important to consider it as a differential diagnosis of chronic suppurative otitis media. Patients who have known or suspected active extra-aural tuberculosis and chronic suppurative otitis media should also be evaluated for tuberculous otitis media(7). The assessment should include a thorough examination of the ear, a chest $\mathrm{x}$-ray and skin testing.

The successful management of patients with otolaryngologic tuberculosis depends on high clinical suspicion, prompt diagnosis, and early initiation of antituberculous therapy. Simultaneous involvement of anatomically related multiple organs by tuberculosis should be kept in mind.

\section{Reference}

1. Hungria H. Otorrinolaringologia. Rio de Janeiro: Guanabara Koogan.2000.

2. Williams RG, Phil M, Douglas-Jones $\mathrm{T}$. Mycobacterium marches back. J Laryngol Otol 1995; 109:5-13.(s)

3. Garcia RID Cecatto SB, Rapoport PB, et al. Tuberculose e blastomicose laringea: relato de tres 
J. Dhaka National Med. Coll. Hos. 2011; 17 (01): 53-55. casos e revisao de literatura. Rev Bras Otorrinol. 2004, 70(2): 255-259.

4. Tuberculosis. In: Benenson AS, ed. Control of communicable diseases manual. $15^{\text {th }}$ ed. Washington, D.C.: American Public Health Association, 1990;459.(s)

5. Skolnik PR, Nadol JB, Jr., Baker AS. Tuberculosis of the middle ear: Review of the literature with an instructive case report. Rev infect Dis 1986;8:403-10.

6. Pinho MM, Kos AOA. Otite Media Tuberculosa, Artigo de Revisao. Rev Bras Otorrinol. 2003, 68(5): 829-837.

7. Kirsch CM, Wehner JH, Jensen A, Campagna AC, et al. Tuberculous otitis media. South Med J 1995; 88: 363-366.

8. Pinto AM, et al. controle da Tuberculose: Uma proposta de Integracao Ensino-Servico. 5a. ed. Rio de Janeiro: FUNASA/CRPHF/SBPT. 2002.236 p.

9. Goldman L, Bennett JC, et al. Cecil, Tratado de Medicina Interna. Rio de Janeiro: Guanabara Koogan. 2001.

10. Kasper DL, et al. Harrison 's, Principles of Internal Medicine. New York: McGraw-Hill. 2004.

11. Shin JE, Nam SY, Yoo SJ, Kim SY. Changing trends in clinical manifestations of laryngeal tuberculosis. Laryngoscope 2000; 110:1950-1953.(s)

12. Lin CJ, Kang BH, Wang HW. Laryngeal tuberculosis masquerading as carcinoma. Eur Arch Otorhinolaryngol 2002;259:521-523.(s)

13. Windle-Taylor PC, CM. Tuberculous otitis media: A series of 22 patients. Laryngoscope, 1980;90: 103944.

14. Weiner GM, O'Connell JE Pahor AL. The role of surgery in tuberculous mastoiditis: Appropriate chemotherapy is not always enough. J Laryngol Otol 1977; 111:752-3. 